responds inadequately to these situations in terms of 11oxysteroid output, and a relative deficiency of these hormones follows, preparing the way for the acute attack.

There are a good many theoretical objections to this theory, but such studies of the hormonal pattern in gout may well lead to a better understanding of this disease and provide important information regarding the function of the adrenal steroids.

\section{Chemical Structure of Fibrinoid}

Fibrinoid change in connective tissue has been regarded as the characteristic lesion in diseases of the collagen group, thus implying that fibrinoid was in some way derived from collagen or its precursors. Kantor and his associates in New York University have now been able to show by chemical and histological methods that this substance is in fact non-collagenous in origin. This observation may be of considerable importance, as it throws doubt upon the view that changes in the structure of collagen form the basis of the pathological lesions in this group of diseases. This is a good example of how the use of combined chemical and histological techniques may provide more accurate information than more conventional methods. This more dynamic approach to the elucidation of the nature of pathological change is likely to have an increasing application, as histochemical techniques are combined with electron microscopy.

\section{Conclusion}

These brief notes on research in the field of rheumatism are far from complete, but may serve to illustrate the diversity of approach and the increasing application of the disciplines of the basic sciences to the solution of problems in the field of medicine. It becomes increasingly obvious that, with advancing knowledge, opportunities for individual research are becoming more limited. The team of scientists, representing many fields of knowledge, has largely replaced the lone worker in the small laboratory. Opportunities for the brilliant individualist still exist, but the co-ordinated activities of a group with the command of many techniques seem likely to contribute more to the store of knowledge in the long run. The place of the clinician in such a team must be clearly defined. There is a tendency at the moment to relegate him to the background along with the patient from whom material for study is obtained. Unless he has additional training in some scientific field, he finds it difficult to get on terms with his laboratory colleagues. It would be unfortunate if this trend were to develop further, as the clinician must ultimately relate new knowledge to the practical problem of applying it to the treatment of disease in the human patient. The clinician must exert himself to grasp at least the principles of scientific methods used in research, and the scientist must unbend enough to make his results and their implications comprehensible to his clinical colleague. Both must consider the best interests of the sick patient when research has produced some new approach to the treatment of his disease.

The Ministry of Health has asked the Liverpool Blood Transfusion Service, together with the Manchester and Cardiff Services, to collaborate with the Medical Research Council in a survey of patients who have received transfusions of irradiated plasma or small-pool plasma, in order to compare the incidence of homologous serum jaundice in the two groups. At present irradiation with ultra-violet light is the most promising method of sterilizing plasma. A control series of cases receiving only blood will also have to be surveyed. It is proposed to provide each hospital in the region with either irradiated or small-pool plasma, but not with both, and to follow up patients who have received either after a period of five months. The survey will last three years.

\section{THE INVOLUTION OF THE CERVIX*}

\author{
BY
}

\section{HUGH C. McLAREN, M.D., F.R.F.P.S.} F.R.C.S.Ed., M.R.C.O.G.

Professor of Obstetrics and Gynaecology, University of Birmingham

Are post-partum erosions normal in the involuting cervix and do they persist if untreated ? The question is important, since the common treatment of erosions after delivery rests on the assumption that they are pathological and give rise to symptoms such as leucorrhoea and backache (Browne, 1946).

Clinically, the cervix often appears to have reached its nulliparous state six weeks after delivery, but a biopsy will show that the changes of pregnancy are still obvious-for example, the stroma is cellular, vascular, and oedematous, while the glands are so numerous as to appear as a honeycomb (Stieve, 1927 ; Fluhmann, 1948; Murphy and Herbut, 1950). In other words, from a histological point of view the cervix, six weeks after delivery, is still in a pregnant state, although involution is proceeding.

In this clinical and histological study, observations on the post-partum cervix were followed by observations on post-natal erosions which were allowed to heal without treatment. The object was to ascertain if the process of involution in cases with erosion differed materially from the normal post-partum case.

\section{Methods of Investigation}

A total of 262 patients were investigated: 121 with postpartum erosions and 141 without post-partum erosions (controls).

The following investigations were carried out approximately six weeks after delivery. First, in every case I completed a standard case-sheet with a detailed description of symptoms such as leucorrhoea and backache. Vaginal smears were then taken and a "Cusco" speculum was passed. A diagram was made outlining the portio and giving details of the amount and type of cervical mucus. The mucous plug was then removed and an endocervical specimen of mucus was taken by an ordinary throat swab for microscopy. The physical properties of the cervical mucus were observed by attempting to draw the specimen out into threads (Spinnbarrkeit). A laryngeal punch was then used to obtain squamo-columnar biopsies, and finally the bleeding area was treated with a nasal-wire cautery.

An attempt was made to correlate simple erosions with symptoms such as backache and leucorrhoea, and therefore complications such as parametritis and fixed retroversion of the uterus were excluded by bimanual examination.

\section{Clinical Results}

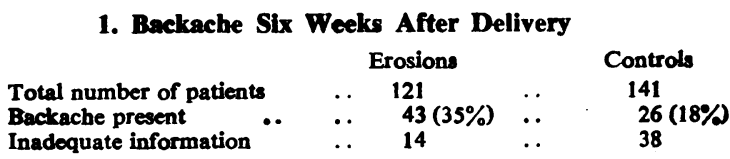

Backache was present in $35 \%$ of patients with erosions and in $18 \%$ of those without erosions. It became obvious after taking a careful history from the patient and examining her back, testing its mobility, and so on, that the cervix could

* Preliminary report, read before the Birmingham and Midland Obstetrical and Gynaecological Society, Nottingham, October 13 1950. 
not possibly be the source of the pain. If the patient, for instance, located the pain as being between her shoulderblades, if rest relieved her pain, or if her backache amounted to stiffness prior to exercise, she was excluded. Correction by this method left $18 \%$ of patients with backaches which could possibly be related to an erosion and $2 \%$ of controls. In the erosion group nine cases were included in which data concerning localization, the effect of movement, etc., were not available, so that $18 \%$ is almost certainly too high. Moreover, by following the progress of patients with backache it became more and more obvious that cervical erosions and backache could not be correlated. First of all, backache becomes uncommon after four to five months, and, secondly, its persistence does not depend on the persistence of a post-natal erosion. For example, of nine patients with persistent backache, six had healed and three had unhealed cervical erosions five months after delivery. Vice versa, persistent erosions five months after delivery were not accompanied by a high incidence of backache.

Although it is admitted that a widely split cervix with an obstetric laceration running up the lateral fornix to an indurated and tender parametrium can cause low backache (Young. 1938 ; Barns. 1948), it seems clear from our observations that cervical erosions, per se, do not give rise to backache. It follows that routine cauterization of cervical erosions for the cure of backache is unwarranted.

\section{Post-natal Lencorrhoea}

Considering the enormous changes in the genital tract during childbirth, it is not surprising that some women should have a vaginal discharge six weeks after delivery. It is a mistake, however, to observe mucus at the lower cervix and to assume without further study that you have discovered the source of discharge. Moreover, if removal of the mucus or mucopus at the portio uncovers an erosion it may be wrong to assume that this is a diseased cervix producing abnormal quantities of mucus or mucopus. In fact, before diagnosing leucorrhoea of cervical origin it is essential to prove that the cervix is the source of discharge.

Incidence of Vaginal Discharge.-Six weeks after delivery $34(28 \%)$ patients with erosions complained of vaginal discharge ; $21(17 \%)$ had only traces. However, $25(18 \%)$ postpartum controls also had vaginal discharge and $20(14 \%)$ had traces. By elimination of traces of discharge, lochia, trichomonas vaginitis, and so on, the incidence of leucorrhoea is corrected to $17 \%$ for erosions and $9 \%$ for controls. Six weeks after delivery, therefore, $17 \%$ of patients with erosions complained of discharge, but this is not remarkable when the normal incidence is $9 \%$. Moreover, by studying the clinical findings at the cervix and comparing them with the patient's symptoms of discharge, we shall endeavour to show that the cervix is seldom the source of discharge.

\section{The Post-natal Mucous Plug}

The physical properties and the cell content of the plug of mucus at the post-natal cervix vary greatly from case to case. There is, however. no typical mucous plug commonly seen in erosions which is not equally common in post-natal controls. so that marked erosions may secrete traces of clear mucus and, vice versa, a normal cervix may secrete abundant mucopus.

\section{Six-weeks Cusco Examination}

\begin{tabular}{|c|c|c|c|c|c|c|}
\hline Cervical Mucus & & & & rosions & & Controls \\
\hline Opaque plug.. & .. & 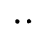 & $\cdots$ & 44 & .. & 59 \\
\hline Trace & .. & . & .. & 15 & .. & 3 \\
\hline Translucent & .. & .. & .. & 30 & .. & 29 \\
\hline Absent & .. & .. & .. & 17 & .. & 37 \\
\hline Inadequate record & .. & .. & .. & 15 & .. & 13 \\
\hline
\end{tabular}

Six weeks after delivery, therefore, the cervical mucous plug is usually bulky but tenacious, while an endocervical

specimen practically never resembles " mid-cycle" mucusthat is, it seldom pours out as a crystal-clear liquid and it cannot be pulled into threads. Perhaps as a result of its tenacious quality, a stream of mucus is rarely seen extending to the vulva, which might be the case if the mucus were of a " runny" character. Whether or not this explanation is valid, there is a surprising lack of correlation between the patient's symptoms of discharge and the volume of mucus at the cervix. For example:

No Leucorrhoea Leucorrhoea

Opaque mucous plug at portio ( 42 cases) $31(74 \%) \quad 11(26 \%)$ Clear mucus, traces, or none (61 cases) $48(79 \%) \quad 13(21 \%)$

It is clear, therefore, that a large mucous plug may exist without discharge at the vulva; on the other hand, a trace of clear mucus at the portio is commonly seen in patients complaining of vaginal discharge.

Microscopical specimens were taken from 100 post-natal erosions and 100 (six-weeks) controls. The important finding was that mucus which appeared clinically to be opaque or even mucopurulent often had but a few polymorphs, the smear consisting of clouds of epithelial cells of many shapes and sizes. Indeed, one-third of all the smears had no pus cells (polymorphs).

Cell-smears from erosions and controls varied from case to case, but there was no preponderance of inflammatory cells in the erosion-smears. With Papanicolaou's staining (Papanicolaou and Traut, 1943), cervical mucus was almost without exception web-like or crenated, although a few specimens were obtained which resembled typical mid-cycle mucus-that is, they had translucent and acellular mucus which presented a pattern of parallel threads.

To summarize: (1) Considering that only six weeks had elapsed since parturition it is not surprising that discharge affected normal patients and those with erosions. (2) Study of the cervical mucous plug suggests that the cervix is seldom the source of vaginal discharge.

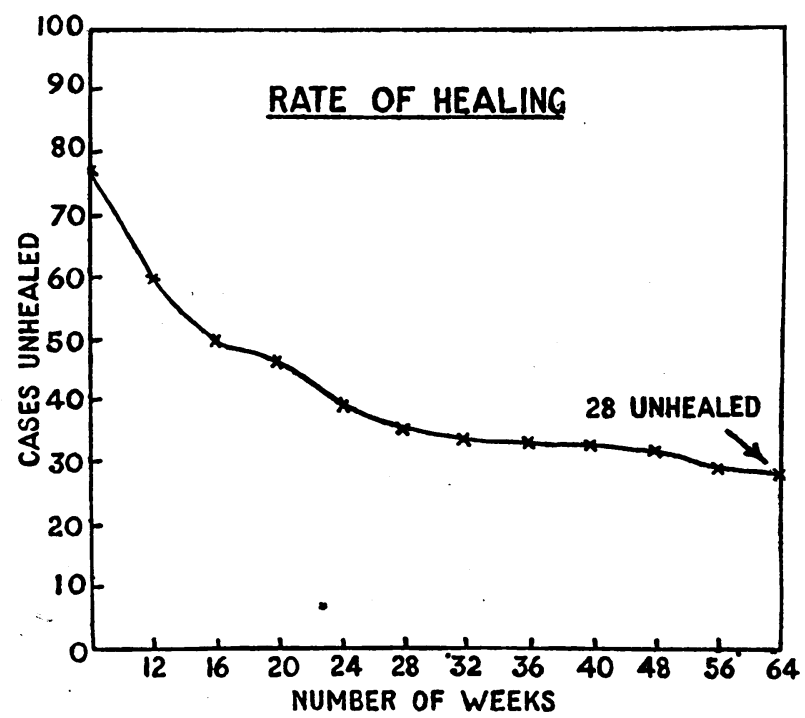

Fig. 1.-Disappearance of cervical erosions without treatment was recorded in 30 out of 77 patients $(39 \%)$ by 20 weeks and in $42(55 \%)$ by 28 weeks. The 28 unhealed erosions have not been observed for 64 weeks, but are at present under observation.

(See text.*)

$\begin{array}{lccccc}\text { Number of cases observed with no treatment } & \ldots & 77 \\ \text { Spontaneous healing } & . . & \ldots & . & \ldots & 49(64 \%) \\ \text { Persistence over } 20 \text { weeks } & . & . & . & \ldots & 28(36 \%)\end{array}$

*The 28 unhealed erosions are at present under observation and tend to heal. The periods af observation are as follows: 20 weeks, 5 erosions; 24,$2 ; 28,2 ; 32,1 ; 36,2 ; 40,5 ; 48,2$; 52,$3 ; 56,2 ; 64,4$. 


\section{Follow-up Study}

At intervals of six to eight weeks 77 patients were re-examined (Fig. 1). They were discharged as "healed" if a small Cusco speculum showed no evidence of an erosion.

If the erosion persisted over five months it was labelled " unhealed." Vaginal smears and, usually, biopsies were then at each visit. It was noted that even six to seven months after delivery the vaginal vault could be distended and the cervix opened to give the appearance of an erosion; in fact, $20 \%$ of our healed patients might have been called cases of persistent erosion if care had not been taken to use a small Cusco speculum, which was allowed to collapse as far as possible.

The result of the non-treatment of 77 erosions, therefore, was spontaneous healing after a variable number of months in 49 cases $(64 \%)$ and persistence in $28(36 \%)$.

The effect of this spontaneous process of healing on leucorrhoea was carefully noted, for it was assumed that the price of non-treatment would be $(a)$ that during the months of observation the patient would suffer from cervical discharge at the vulva, and $(b)$ that finally the unhealed cases would require cautery. In fact, however, not many of our patients under observation were troubled with discharge, and only a few eventually required cauterization.

\section{Cervical Healing and Leucorrhea}

(a) Leucorrhoea in 49 healed erosions: No discharge 6 weeks post partum $\ldots \quad$.. 28 cases

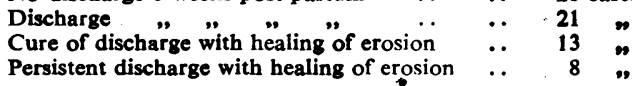

(b) Leucorrhoea in 28 unhealed erosions:

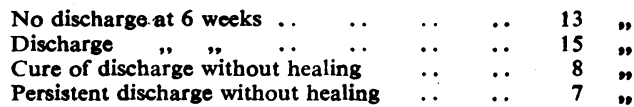

The final number of patients with discharge was eight with healed erosions where the cervix was probably not the source of discharge and seven where discharge and persistent erosion coexisted. Details of these seven cases are of interest as they represent the patients whose symptoms finally required treatment:

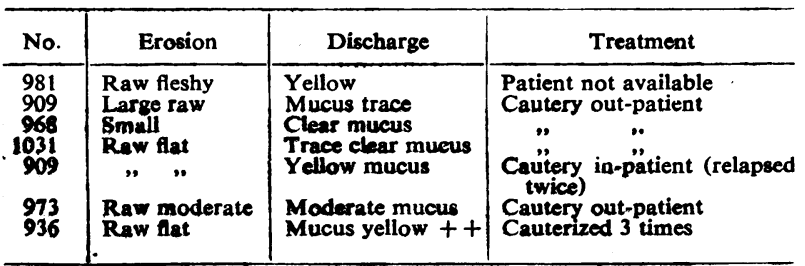

The final result of non-treatment of 77 cases was that 28 had persistent erosions, which were associated with vaginal discharge in seven; in four out of these seven cases repeated examination made it obvious that the discharge was of cervical origin and could be cured by cautery. In other words, of the whole series of 77 cases only four cases of persistent erosion gave rise to symptoms demanding cauterization.

One case (No. 936) was of especial interest since the patient relapsed twice after cautery and produced copious amounts of clear acellular mucus of " runny" character (" mucorrhoea"). Her final cervical biopsy (from the edge of the erosion) showed a normal involuting cervix.

The following conclusions therefore seem to be permissible: (1) Post-natal erosions tend to heal and should not be treated as a routine measure six weeks after delivery. Review of the patients after 20 or 30 weeks may show an asymptomatic erosion or complete healing. (2) Cervical erosions proved to be a source of vaginal discharge should be singled out for eautery about 20 weeks after delivery.
(3) Simple observation of post-natal erosions will leave perhaps $5-10 \%$ of cases with symptoms which demand treatment by cautery.

\section{The Endocrine Background to Erosions}

At the outset of this study we had accepted the common belief that post-natal erosions are not physiological but pathological, and that they could give rise to symptoms akin to those arising from the common erosion of gynaecological practice (Arthure, 1938; Ross, 1950). A search was therefore made for some clue to the causation-for example, to ascertain if senile or poorly developud vaginal smears were commonly present with erosion in contrast to the normal. Note was also made of the time of cessation of lactation and duration of amenorrhoea, as well as the appearance and physical properties of cervical mucus, but there was apparently no correlation between these observations and the onset or persistence of erosion. For example, erosions persist or disappear irrespective of whether ornot the patient has begun to menstruate or has ceased to lactate, and, as we have stated above, the physical and cytological properties of cervical secretions do not depend on the presence of an erosion

\section{Vaginal Smears}

The common vaginal smear of pregnancy is peculiar in that clumping is common with surface cells, which are small (15-20 $\mu$ diameter). In the depth of the clump of cells there can be seen larger cells, somewhat flattened and $40-50 \mu$ in diameter, with well-defined nuclei. These "pregnancy" or "luteal" smears have a variable number of polymorphs, while their persistence is remarkable even six months after parturition. A less common smear represents different layers of the mucosa, and these have been labelled " mixed," grade II, and grade I (stratum germinativum cells) according to their lack of maturity. The smear containing large flat squamae (as in an oestrogenic or mid-cycle smear) is rare. In the series of cases under review vaginal smears were taken six weeks after confinement, and the results of examination were as follows:

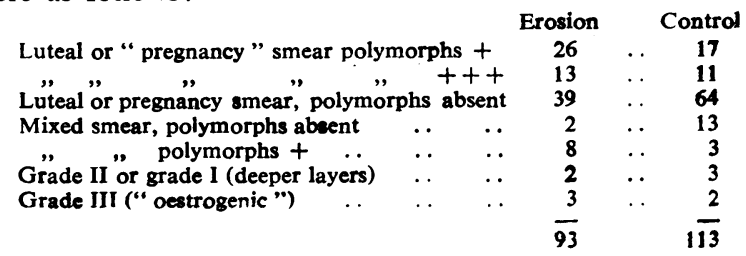

Although admittedly vaginal cytology is a very rough gauge of ovarian function, the following conclusions are made: (1) post-partum senile smears are rare-that is, the vaginal mucosa is seldom atrophic; (2) the common smear is of intermediate type, obviously from mature vaginal mucosa $(82 \%)$; (3) the maturity of cell-smears bears no relationship to the presence of erosions. It must be stated, however, that no attempt was made to take the specimens at the estimated mid-cycle. Finally, no correlation is possible between the maturity of vaginal smears and the persistence or healing of erosions.

That our search for the aetiology of post-natal erosion failed is not surprising if the thesis which we shall try to establish is accepted-namely, that post-natal erosions are physiological.

\section{Cervical Histology}

A different biopsy site was chosen at subsequent examinations, but both in normal cervices and in clinical erosions the squamo-columnar edge was the target. A laryngeal punch obtained small specimens measuring about 5 by 2 by 2 or $3 \mathrm{~mm}$. deep. No vulsellum or local analgesic was used, although a nasal-wire cautery was necessary to stop the bleeding. 
The outstanding observation was that the effects of pregnancy persist for months after delivery, although the cervix may clinically appear normal. Secondly, biopsies from erosions often resemble normal (involuting) tissue. To demonstrate this, the changes of pregnancy are tabulatedfor example, if the glands are still "pregnant" they are numerous to the extent of resembling a cross-section of a honeycomb, or if the stroma is still pregnant it is cellular or lacks intercellular substance.

\section{Definitions}

1. (a) Glands +++ : Numerous glands up to a "honeycomb" effect. Columnar epithelium usually tall, actively secreting mucus (Fig. 2, B). (b) Glands absent: Either the

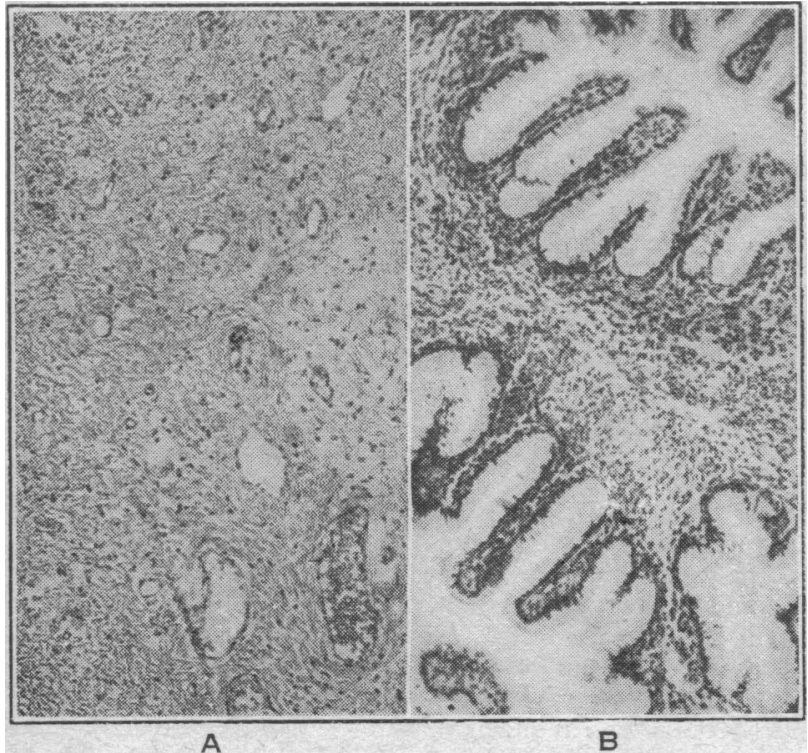

Fig. 2.- (A) Normal stroma. (B) Residual pregnancy-effects six weeks after delivery. Pregnancy causes the mucous glands to proliferate, while the stroma is converted to a cellular structure. Lymphocytes and plasma cells are common in the stroma of pregnancy.

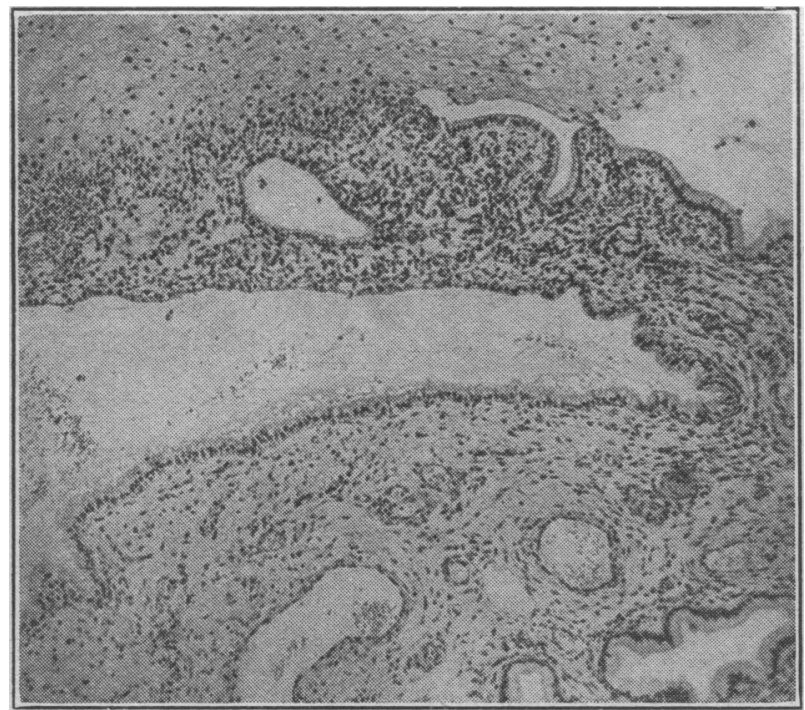

Fio. 3.-Erosion six weeks after delivery-classified histologically as non-inflammatory-that is, the erosion amounted to an area of columnar epithelium on the portio. Round-cell infiltration of the stroma at the squamo-columnar junction is so common a finding that it can be taken as normal. The rest of the section was practically free from round cells. glands were not reached or in the squamo-columnar area no glands were present at the limits of the punch. (Biopsy about $3 \mathrm{~mm}$. deep.)

2. (a) Stroma cellular: Connective-tissue cells packed together or separated by oedema; scanty intercellular fibrils (Fig. 2, B). (b) Hyaline : Relatively acellular connective tissue; up to a year or more after delivery delicate intercellular fibrils predominate. (As involution proceeds this tissue spreads towards the glands from below the squamous epithelium.)

3. Inflammation: Inflammatory processes were seldom more than mild, and amounted to no more than stromal infiltration by round cells. Desquamation was rarely seen. (a) No inflammation: Subepithelial infiltration by lymphocytes confined to a small clump around the squamocolumnar junction (Fig. 3). (b) Mild round-cell inflammation: Lymphocytes and sometimes plasma cells infiltrating the subsquamous and periglandular stroma (Fig. 4). (c) Subacute inflammation: Dilated capillaries with polymorphs, lymphocytes, and plasma cells in the stroma deep to the mucous and squamous epithelium (Fig. 5).

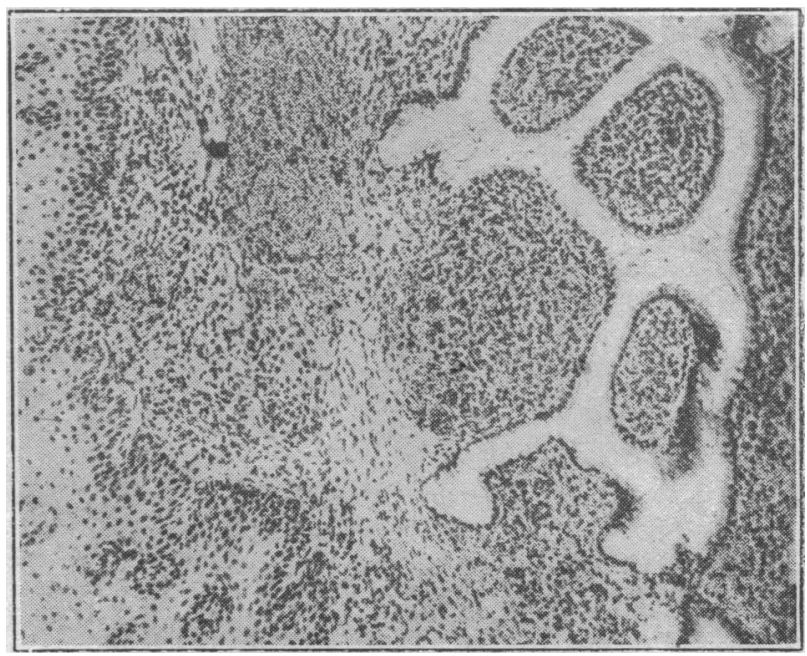

FIG. 4.-Squamo-columnar biopsy of normal cervix six weeks post partum. Marked round-cell infiltration of stroma, especially near mucous glands; classified in the text as "mild round-cell infiltration."

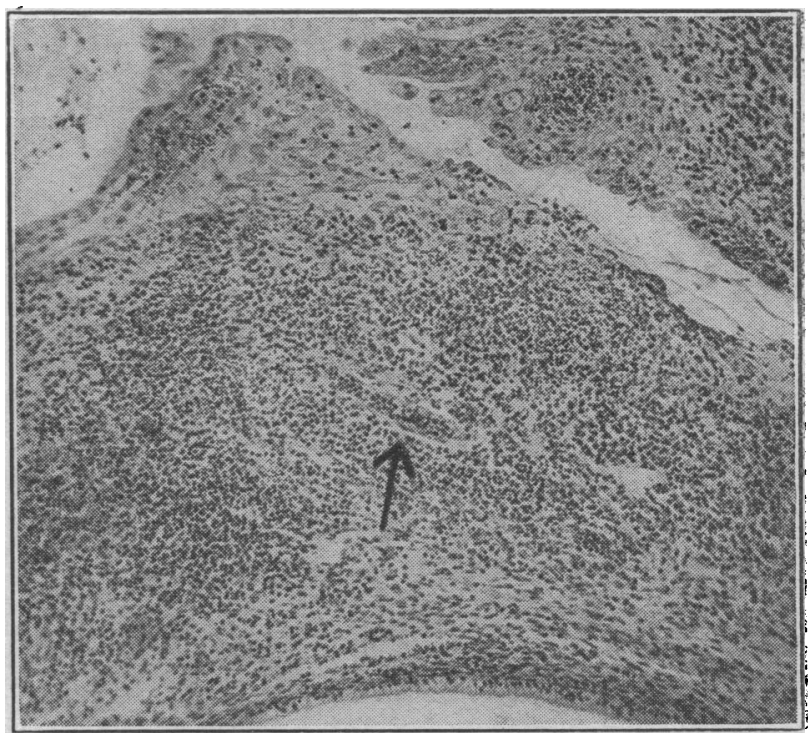

FIG. 5.-Squamo-columnar junction of an erosion six weeks after delivery. Subacute inflammation with capillaries (arrow) packed with polymorphs and lymphocytes. Subacute inflammation is rare in erosions and controls. 
Histology Six Weeks After Delivery (Fig. 6)

1. Mucous glands: Numerous secreting $\quad \ldots \quad 66(89 \%) \quad \ldots \quad 37(58 \%)$

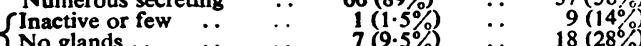

2. Stroma :

Cellular (still " pregnant ") $\quad 61(82 \%) \quad$.. $\quad 32(53 \%)$

$\{$ Hyaline (delicate tibrils) .. $\quad 11(15 \%) \quad \ldots \quad 18(30 \%$

3. Inflammation

None 1 ild round-cell infiltration

(only at the surface only at the surface in epithelium ; 9) ... ..

Subacute (only at the sur-

facute (only at the surface in tips of folds of

$26(35 \%)$

.. $38(65 \%)$

$35(47 \%) \quad \ldots \quad 16(26 \%)$

$13(18 \%) \quad \ldots \quad 5(9 \%)$
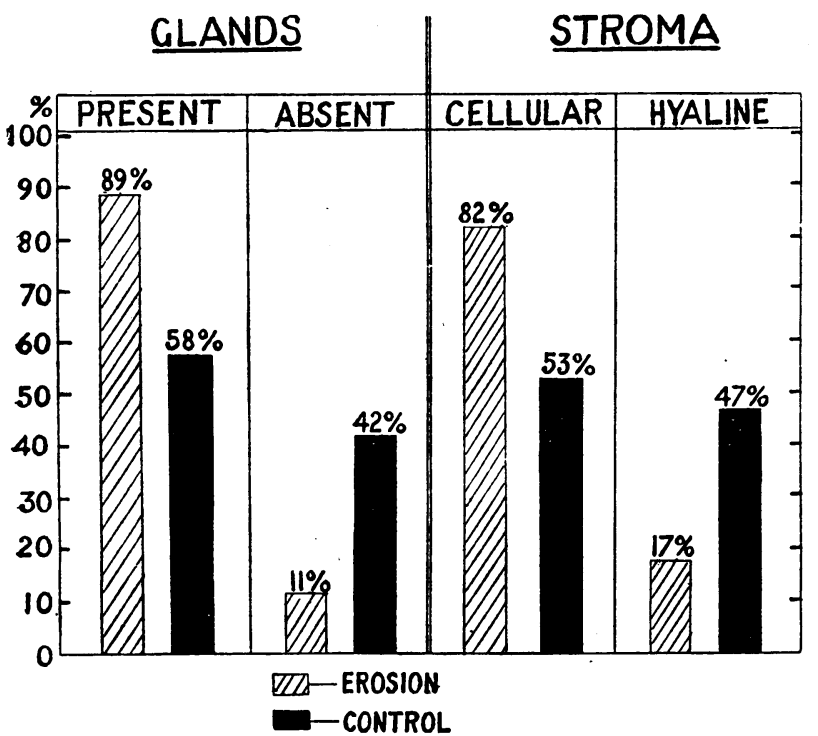

Fig. 6.-Gland activity of pregnant type was common to erosions and controls, but in the controls the biopsy failed to reach the glands in 18 cases and showed a few in 9 (total 42\%). In

erosions the stroma tends to be more cellular than in controls.

Six weeks after delivery, therefore, squamo-columnar biopsies from normal cervices resemble those from the edge of post-natal erosions. Both show persistent pregnancy effects such as a massive gland pattern -with apparently active secretion: in both, the stroma is cellular, while inflammatory reactions such as infiltration of round cells and dilated capillaries are common. It is important to note that inflammation is confined to the surface of the cervix and is generally of mild type without desquamation (Figs. 3 and 4).*

Miscellaneous Findings.-Less common pregnancy effects were also observed, such as metaplasia, phagocytosis of hyaline tissue by fibroblasts, "Hofbauer" cysts, and so on (Hofbauer, 1933). Stromal oedema, sometimes with effusion of red cells, was common in six-weeks specimens, but decidual cells as described by Sheets (1948) and McIlrath and Hellestrand (1947) were not observed. Hyperplastic cells in the deeper layers of the squamous epithelium were also occasionally seen, but there was nothing resembling intraepithelial cancer (Danforth, 1950).

\section{Advancing Involution}

Seventy-seven squamo-columnar biopsies from both healed and persistent erosions were taken at intervals up to a year after delivery. By contrasting them with 142 specimens obtained six weeks after delivery it was possible to observe the slow process of involution as it affects mucous

*Robert Meyer's (1910) dictum, “Ohne Entzundung keine Erosion," might place most of this group among the congenital non-inflammatory types of erosion. glands, stroma, resolution of inflammatory reaction, and so on. Secondly, biopsies from the squamo-columnar edge of persistent erosions were compared with biopsies from healed cervices.

The outstanding change in the cervix with the passage of five to six months is in the stroma, which gradually changes from its "pregnant" or cellular state to a more fibrous or acellular structure (Fig. 7). The cellular stroma first disappears in the lower cervix beneath the squamous epithelium of the portio, but tends to persist around mucous glands or near small foci of inflammation. Soon after delivery the pregnant close-packed cellular stroma is replaced by young fibrous tissue with delicate fibrils of intercellular substance. This new fibrous tissue gives way to connective tissue possessing coarser intercellular substance. But in our sections, taken up to 12 months after delivery, the nonpregnant acellular stroma was seldom completely reproduced (com pa re Figs. 2A and 7).

Three to four months after delivery oedema of the stroma disappears, while the widely dilated and numerous capillaries in the stroma also disappear.

Inflammatory c e $11 \mathrm{~s}$

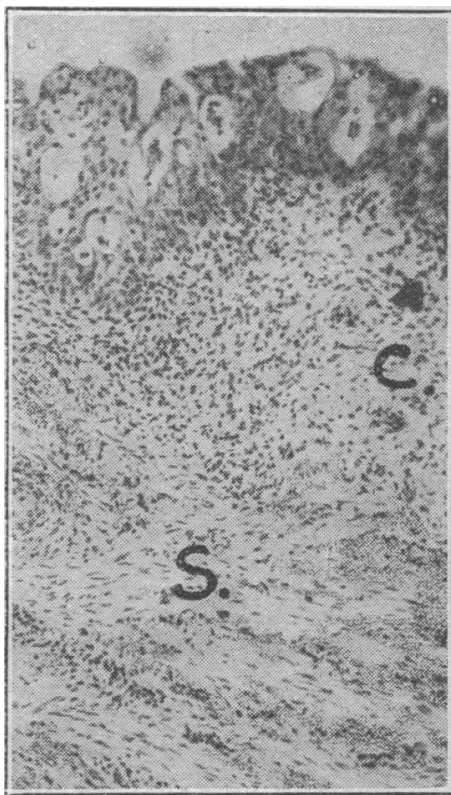

Fig. 7.-Persistent erosion 12 months post partum. Replacement of cellular stroma (C) by more acellular tissue (S) is not yet complete. Note the cystic appearance of the squamous epithelium.

tend to become less prominent, but even months after delivery scattered foci or diffuse areas of round cells are still common (Fig. 8). By six or seven months the mucous glands become less numerous, and our biopsies often failed to reach gland tissue-that is, the mucous glands not only diminish in number but appear to retract from the lower cervix.

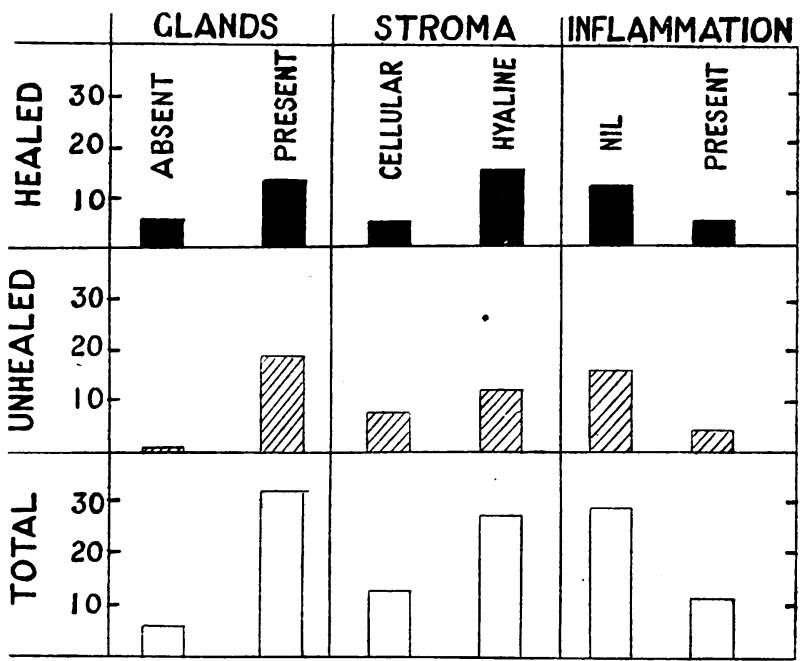

Fig. 8. - The effects of involution of cervical erosion ( 40 cases) at 20 weeks are present in the cervix with or without an erosionnamely, the glands become less prominent, the stroma loses its cellularity, while inflammation diminishes. 
By taking a sample of 20 specimens from persistent erosions and 20 erosions which had healed spontaneously, it is easy to show that the changes of involution affect not only erosions which persist but also those which show clinical healing (Fig. 8). Thus if a pathologist could be persuaded to give his opinion on one of our small biopsies he would have great difficulty in deciding if the specimen came from the squamo-columnar edge of a normal cervix or from an unhealed erosion. In both there would be evidence of advancing involution affecting glands, stroma, and inflammatory cells.

\section{Non-treatment of Post-partum Eresions}

Bourne and Bo..d (1939-40) found it difficult to correlate cervices amputated for (clinical) chronic cervicitis with the histology, which often appeared to show no more than mild surface inflammation. Fluhmann (1948), on the other hand, in an important study of the histology of the erosions of pregnancy refers to the clinical condition as the "so-called erosion" of pregnancy. Nevertheless, in many clinics postnatal erosions are diagnosed as pathological six weeks after delivery, and routine cauterization is carried out. Two obvious criticisms of non-treatment of erosions might be made-namely, that post-natal erosions might be a source of discharge, and, secondly, they might lead to future sterility.

It has already been mentioned that few of our untreated cases of erosion were subject to mucous discharge of cervical origin ; in fact, of the total of 77 cases only 4 (5\%) finally had true "mucorrhoea" from erosions of the cervix. It is not suggested, however, that in non-pregnant women erosions never cause leucorrhoea; for, either by repeated Cusco examination in out-patients or by a tampon test, it is occasionally possible to prove that a patient's discharge arises in the cervix. It seems clear to us from this clinical study, however, that the cervical mucus of the post-partum cervical erosion seldom reaches the vulva in amounts to cause leucorrhoea.

Secondly, our observations on the 28 cases of persistent erosion do not suggest that sterility from impenetrable cervical mucus results from non-treatment. In fact, clear or acellular mucus is commonly secreted from large postnatal erosions, persisting for months after delivery, as in the following case:

A married woman aged 22 . On three occasions endocervical spermatozoa were obtained in smears of translucent endocervical mucus. The patient had not been instructed to have coitus before presenting herself for examination. Eight months after delivery she was pregnant, still with a large erosion.

Four other women with persistent erosions became pregnant and continued to have erosions in early pregnancy, so that it appears unlikely that the untreated and persistent erosions provide a barrier to further conception.

Although it is known that pregnancy predisposes to cervical cancer (Ministry of Health Reports, 1927), the relation of post-natal erosions to the future development of cancer is unknown, and there is no evidence to show that cautery of the cervix as practised in the out-patient department with a " nasal-wire" cautery (as opposed to thermal destruction of the lower cervix) (Cashman, 1941, 1945) can prevent cancer. In fact, only a few millimetres of mucous epithelium are burned by the cautery in out-patients and are replaced by squamous epithelium. The majority of our young patients; however, will be pregnant several times in the ensuing years, and on each occasion, so to speak, they will grow a new cervix with or without an erosion-that is, in the antenatal and post-natal period the cervix will undergo a complete metamorphosis. In the light of these changes in the physiology of the cervix it is difficult to regard surface cautery of the post-natal cervix as being able to influence the future behaviour of the epithelial tissue of the cervix.

\section{Conclusions and Summary}

It seems clear to us from this clinical study that postpartum cervical mucus, possibly owing to its tenacious quality, seldom reaches the vulva in amounts to cause leucorrhoea. Post-natal erosions are, in fact, innocuous, and, although it is possible in a few cases to prove that vaginal discharge arises from them, in most cases the cervix is not the source. Treatment should therefore be reserved for persistent erosions proved to be the cause of "mucorrhoea."

Post-natal erosions usually resolve without treatment.

Post-natal erosions as well as normal post-natal cervices can occasionally be shown to cause "mucorrhoea" six weeks after delivery.

Persistent erosions are usually innocuous, but excessive mucous discharge may demand treatment by cautery $(5 \%)$.

\section{Post-natal erosions do not cause backache.}

Squamo-columnar biopsies from normal cervices and from erosions show post-partum involution; biopsies from the edge of healed or persistent erosions are similar ; both depict advancing involution.

Post-natal erosions are physiological, and cauterization is seldom indicated.

I wish to acknowledge gratefully the help I have received from my colleagues on the staff of the Birmingham Maternity Hospital, and especially Dame Hilda Lloyd, Mr. Charles D. Read, and Professor S. Zuckerman for their criticism and advice. I also wish to thank our unit sister, Miss M. Scott-Will, and senior technician, Miss M. E. Attwood, for their enthusiasm and help in conducting this investigation.

\section{REFERENCES}

Arthure, H. (1938). J. Obstet. Gynaec. Brit. Emp., 45, 985.

Barns, H. H. F. (1948). Practtioner, 160, 68

Bourne, Alec, and Bond, L. T. (1939-40). Proc. roy. Soc. Med., 33, 787

Browne, F. J. (1946). Antenatal and Postnatal Care. Churchill, London.

Cashman. B. Z. (1941). Amer. J. Obstet. Gynec., 41, 216.

- (1945). Ibid., 49, 190.

Danforth, D. N. (1950). Ibid., 60, 985.

Fluhmann, C. F. (1948). Ibid., 55, 133

Hofbauer, J. (1933). Ibid., 25, 779.

Mclirath, M. B., and Hellestrand, A. L. (1947). J. Obstet. Gyhaec. Brit. Emp., 54, 746 .

Meyer, R. (1910). Arch. Gynäk., 61, 579.

Ministry of Health Reports on Public Health and Medical Subjects (1927) No. 47. H.M.S.O., London.

Murphy, E. J., and Herbut, P. A. (1950), Amer, J Obstet, Gynec, 59, 384. Papanicolaou, G. N., and Trauc, H. F. (1943). Dlagnosts of Uterine Cancer. The Commonwealth Fund, New York.

Ross, Jean, R. W. (1950). British Medical Journal, 2. 647

Sheets, M. V. (1948). West J. Surg. Obstet. Gynec., 56, 317

Stieve, H. (1927). Der Halsteil der menschlichen Gebärmutter. Akad. Verlags, Leipzig.

Young, J. (1938). Brtitsh Medical Journal, 1, 105.

In Korea, the Assistant Director of Medical Services of the Commonwealth Division, Colonel G. Anderton, told a Daily Telegraph Special Correspondent (January 29), the health of the troops could not be better. Sickness rates in the summer were well below what was expected, and now the incidence of sickness and cold injuries was lower than in any other campaign. Manchurian fever, however, was still causing anxiety. Since July there have been 70 cases in the division; 16 were reported last montb, but the incidence was decreasing with the colder weather. The death rate was between $7 \%$ and $10 \%$. Work was being carried out on the disease, but so far the organism had not been isolated. All cases in the division are referred to the American hospital at Seoul, where the experiments are being done, and tons of poison have recently been distributed in a drive against rats and mice, which are suspected of carrying the infection. 